\title{
Computation of Micro-Strains in Cold Formed Steels- FEA Approach
}

\author{
Assad Anis \\ Department of Automotive \& Marine Engineering, NED University of Engineering \& Technology, Karachi, Pakistan \\ Email address: \\ soi_assad@hotmail.com \\ To cite this article: \\ Assad Anis. Computation of Micro-Strains in Cold Formed Steels- FEA Approach. International Journal of Mechanical Engineering and \\ Applications. Vol. 5, No. 5, 2017, pp. 275-281. doi: 10.11648/j.ijmea.20170505.16
}

Received: December 24, 2016; Accepted: January 6, 2017; Published: October 30, 2017

\begin{abstract}
This paper describes the computations of micro-strains at inner corner of cold formed rectangular hollow sections (CFRHS) made up of structural steels using finite element analysis. In order to obtain the micro-strains, distortion test is simulated by modeling two-dimensional structural steel tubes in ANSYS software. Two dimensional linear static analyses are performed by defining elastic properties of steel. These simulations were performed for tubes with outer radius to thickness $\left(r_{o} / t\right)$ ratios of 3 . In real distortion tests, the direction of force at outer corner of the tube may vary in terms of angle. Therefore, this fact is taken into account while performing simulations. One more aspect is taken into consideration which is related to strain gauge placement during distortion testing. This problem is analyzed by modeling three-dimensional structural tubes and performing linear static analyses to investigate the variations in strains at inner bent section of the tube with different strain gauge locations.
\end{abstract}

Keywords: CFRHS, Finite Element Analysis (FEA), $\mathrm{R}_{\mathrm{o}} / \mathrm{T}$ Ratio, Distortion Testing

\section{Introduction}

A high-strength cold-formed rectangular hollow section structural beam (CFRHS) subjected to cyclic bending loading was found to fail due to fatigue [1]. These members are often used in marine and off-shore applications. Distortions tests (fig. 1) are performed to obtain the fatigue strength of cold formed high strength structural tubes. It is essential to compute the micro-strains at inner corner of the tubes if a strain based fatigue approach is used. The main factors which affect the fatigue strength of cold formed members are residual stresses, stress concentration factors, corners geometry and surface roughness. Many researchers have adopted different techniques to investigate these factors. Sami and Bjork [2] investigated the fatigue crack paths in cold formed corners using FEA approach. The author of this paper has also investigated residual stresses and stress concentration factors in CFRHS [3, 4, 5]. Marquis and Bjork investigated fatigue crack paths in corners of cold formed high strength steels [6]. Mohamed Dabaon [7] investigated built up cold formed sections battened column. Strains were measured in this work to observe failure mode and deformed shapes. Nanocrystalline $\mathrm{Ni}$ and $\mathrm{Ni}-\mathrm{Fe}$ alloys produced by electrode position were characterized by Jason D. Giallonardo [8] using high-resolution transmission electron microscopy (HR-TEM) and X-ray diffraction (XRD). The microstrains in the sample were determined from XRD pattern analysis based on line broadening. X L Xu [9] studied microstrain in rapidly solidified structures of hypercooled $\mathrm{Co}_{80} \mathrm{pd}_{20}$ alloys. In the undercooling range studied, the microstrain in the rapidly solidified structures increases with increasing undercooling. Quenching immediately after rapid solidification is helpful to preserving the microstrain in the microstructures. Cheng $\mathrm{Yu}$ and Benjamin W. Schafer investigated failure modes by performing distortion buckling test in cold formed members [10]. These distortional buckling tests also provide a direct comparison against the local buckling tests previously performed by the writers. Sammy C. W, Lau and Gregory also performed distortional buckling tests of cold formed channel sections [11]. The results of compression tests of thin-walled channel section columns formed by brake-pressing are described. A total of 68 channel section columns of different section geometries, thicknesses and steel grades were tested under uniform 
compression in fix-ended condition. R. Kandasamy, R. Thenmozhi, L. S. Jeyagopal, performed tests on flexural buckling (Lateral - Torsional) of cold-formed steel(CFS) lipped Channel beams under restrained boundary conditions [12]. Thomas H.-K. Kang, Kenneth A. Biggs, and Chris Ramseyer investigated different buckling modes, determine the buckling mode and maximum buckling capacity of the built-up C-channels, and evaluate the AISI-2001 Specification [13]. However the research in determination of micro-strains using FEA at cold formed corners is very unique. Distortion tests are used to solve this problem but the major issue is the proper placement of the tubes in fixture of the hydraulic machine and strain gauges at the inner curved corners of the sections. Therefore a finite element approach is used in this work to compute the strains at the corners of CFRHS.

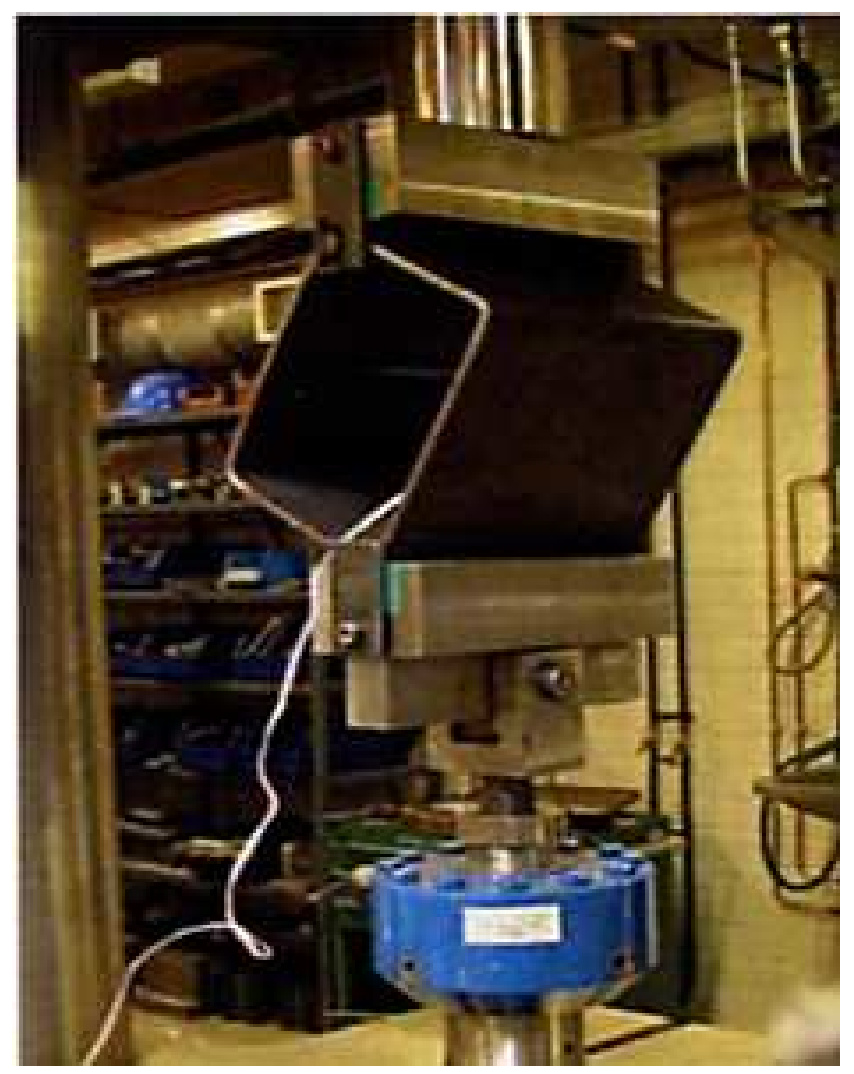

Figure 1. Distortion testing of CFRHS.

\section{Modeling Strategy}

Finite Element Analysis approach is used to find the elastic micro-strain at the middle of the inner side of CFRHS. Twodimensional analysis is performed by using 2D Solid Element (PLANE42) to obtain the strains at the middle of the inner corner of the lower loaded side of the tube by varying force end (lower side, fig 2) and the other end (upper side, fig.2) locations. A three-dimensional analysis is carried out by using 3D solid element (SOLID 95) to find the behavior of the strain at the middle of the inner corner of the lower loaded side of the tube with different strain gauge locations. This is done to investigate the effect of misalignment of strain gauges at the inner corner of CFRHS during distortion tests. The parameters used for modeling CFRHS are listed in table 1.

Table 1. Parameters for Analysis.

\begin{tabular}{lllll}
\hline $\begin{array}{l}\text { Width of } \\
\text { the Tube, } \\
\boldsymbol{b}, \mathbf{m m}\end{array}$ & $\begin{array}{l}\text { Height of } \\
\text { the Tube, }\end{array}$ & $\begin{array}{l}\text { Thickness } \\
\boldsymbol{h} \mathbf{~ m m}\end{array}$ & $\begin{array}{l}\text { of the Tube, } \mathbf{~ m m} \\
\text { of the Tube, } \boldsymbol{r}_{\mathbf{o}},\end{array}$ & $\begin{array}{l}\text { Inner Radius } \\
\text { of the Tube, } \boldsymbol{r}_{\boldsymbol{i}}, \\
\mathbf{m m}\end{array}$ \\
\hline 135 & 180 & 5 & 15 & 10 \\
\hline
\end{tabular}

The following factors were considered for FEA of CFRHS,

- Modeling of CFRHS

- Meshing the model

- Method of Loads

- Boundary Conditions i.e. defining constraints

Since there is no symmetry in the geometry, loading or boundary conditions, therefore, full tube is modeled in Ansys. Two different kinds of models have been developed for analysis i.e. 2D model and 3D- model. In both models the force of $1 \mathrm{kN}$ is applied at middle of the outer corner of lower side of the tube while the other side is pinned as shown in fig 2.

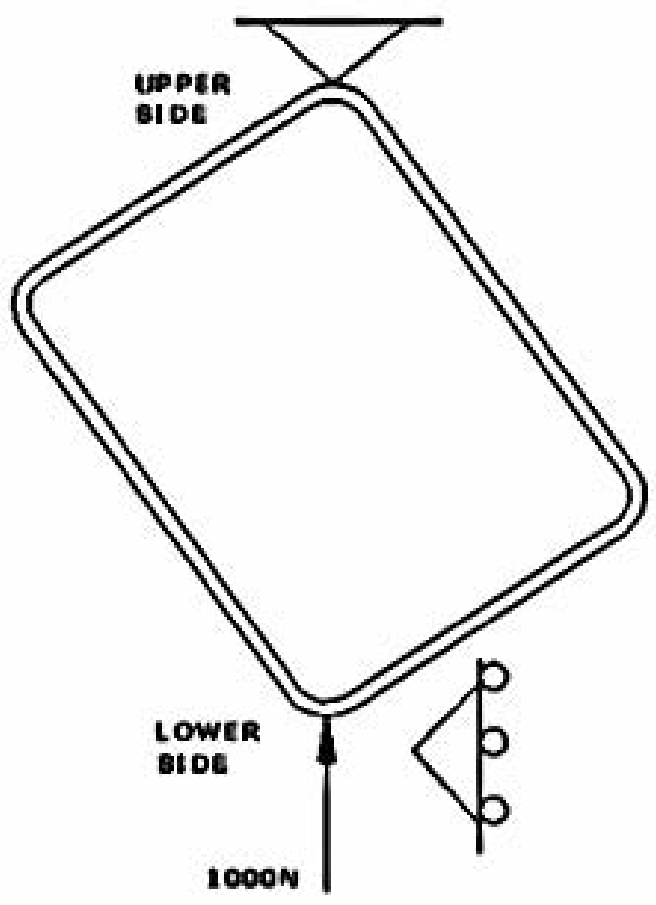

Figure 2. Model of CFRHS for Analysis.

SOLID 2D element i.e. PLANE 42 element is chosen for two-dimensional analyses while SOLID95 is selected for three-dimensional analyses. Linear elastic FEA has been performed by defining the material properties of the steel i.e. Modulus of elasticity $(E)=210,000 \mathrm{MPa}$, and Poisson's Ratio $=0.3$. Mapped meshing is used (fig. 3) for both models with element size of 2 . 


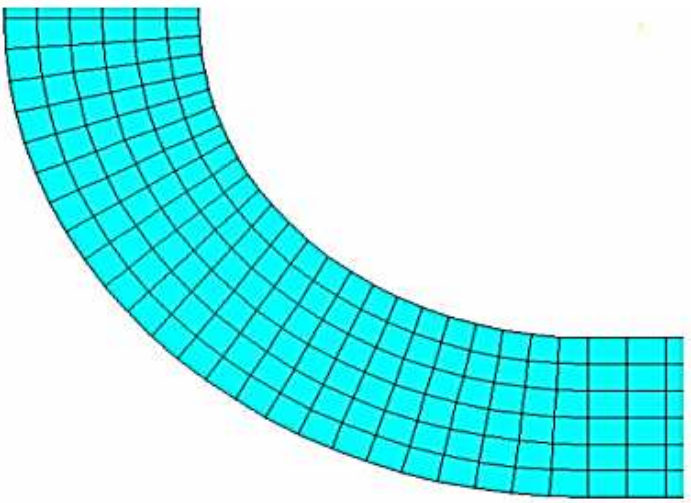

2D- Meshing

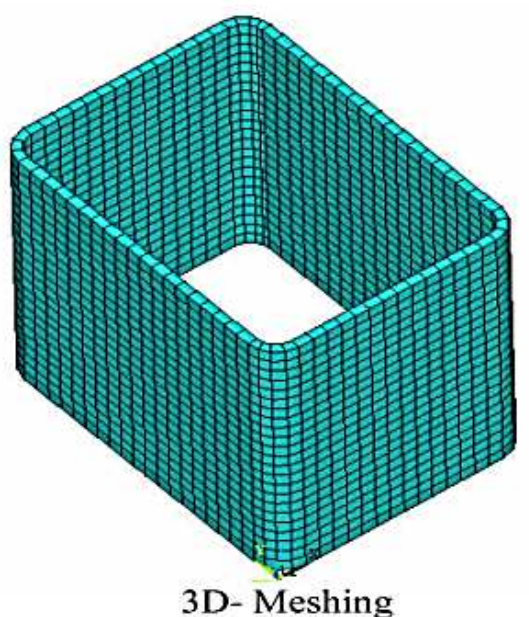

3D- Meshing

Figure 3. Meshed Models.

\subsection{Two-Dimensional Analysis}

Five different approaches have been used to perform 2D analysis to investigate the effect of change in magnitudes of elastic strain at the middle of the inner corner of the lower loaded side of the tube. This is achieved by changing either the position of point of application of the force or the position of the pinned end or both.

\subsection{Modeling Strategy}

- In the first case the force is applied at the middle node of the outer section along $x$-axis and the middle node at the other end (pinned) is fixed in $x$ and $y$ directionsideal case (fig. 6).

- In the second case, force is applied at the middle node but not along any axis. It is applied at certain angles to $\mathrm{x}$-axis but the point of application is the middle node at the lower side of the tube. The position of the pinned end at upper side of the tube and its angle is obtained from the CAD software (AUTOCAD2002) as shown in fig. 6 .

- In this case the force is applied on different nodes i.e. firstly $5 \mathrm{~mm}$ and $10 \mathrm{~mm}$ in positive y-direction from middle node at lower side then $5 \mathrm{~mm}$ and $10 \mathrm{~mm}$ in negative y-direction from the middle node at different angles. The position of the fixed point is again acquired from CAD software.

- In fourth case the position of the middle node at upper side is fixed while the force is applied in the same manner as in case 3 (fig. 6).

- In fifth case the force is applied on the middle node at lower side of the tube while the position of pinned end is varied. All these cases are listed in table 3.

\subsection{Three-Dimensional Analysis}

The 3D analysis is performed to find out the behavior of the strains in the middle of the tube where the strain gauge is positioned as shown in fig. 4 . In reality the strain gauge may not be properly aligned to the inner surface of the tube so finite element approach has been used to find out the behavior of the strains. To address this issue, two analyses have been performed with three different strain gauge positions mentioned in table 2 .

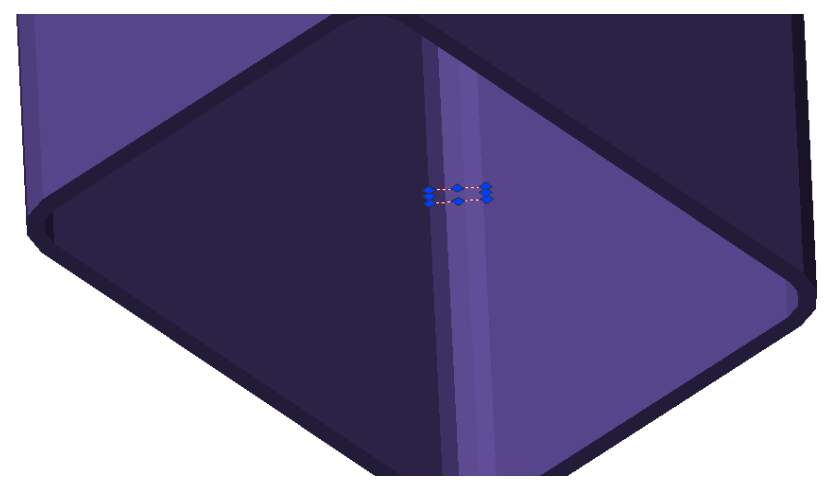

Figure 4. Strain Gauge attached in the centre position at the inner side of the corner.

Force is applied at the middle of lower side corner while the other end is pinned and analyses have been performed for finding the strain in the middle of the inner radius of the tube. Cylindrical coordinate system has been placed as shown in the figure 5 to plot the strain behavior.

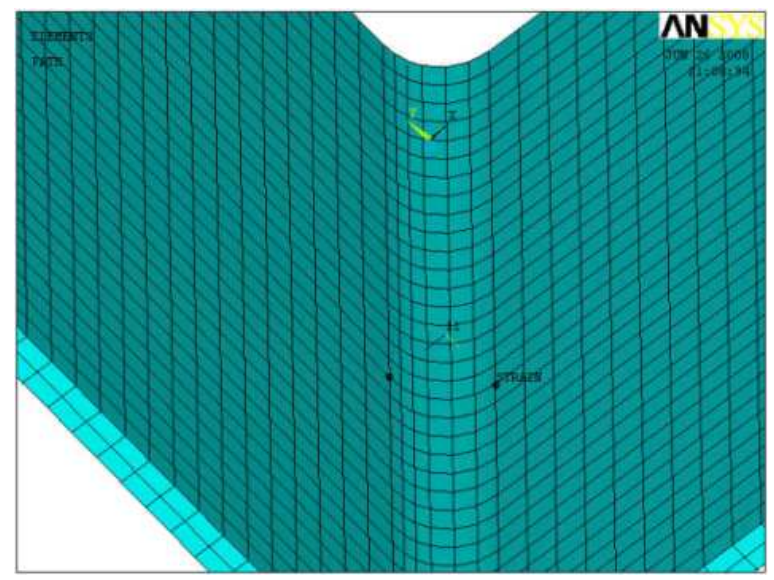

Figure 5. Three-dimensional model of CFRHS. 


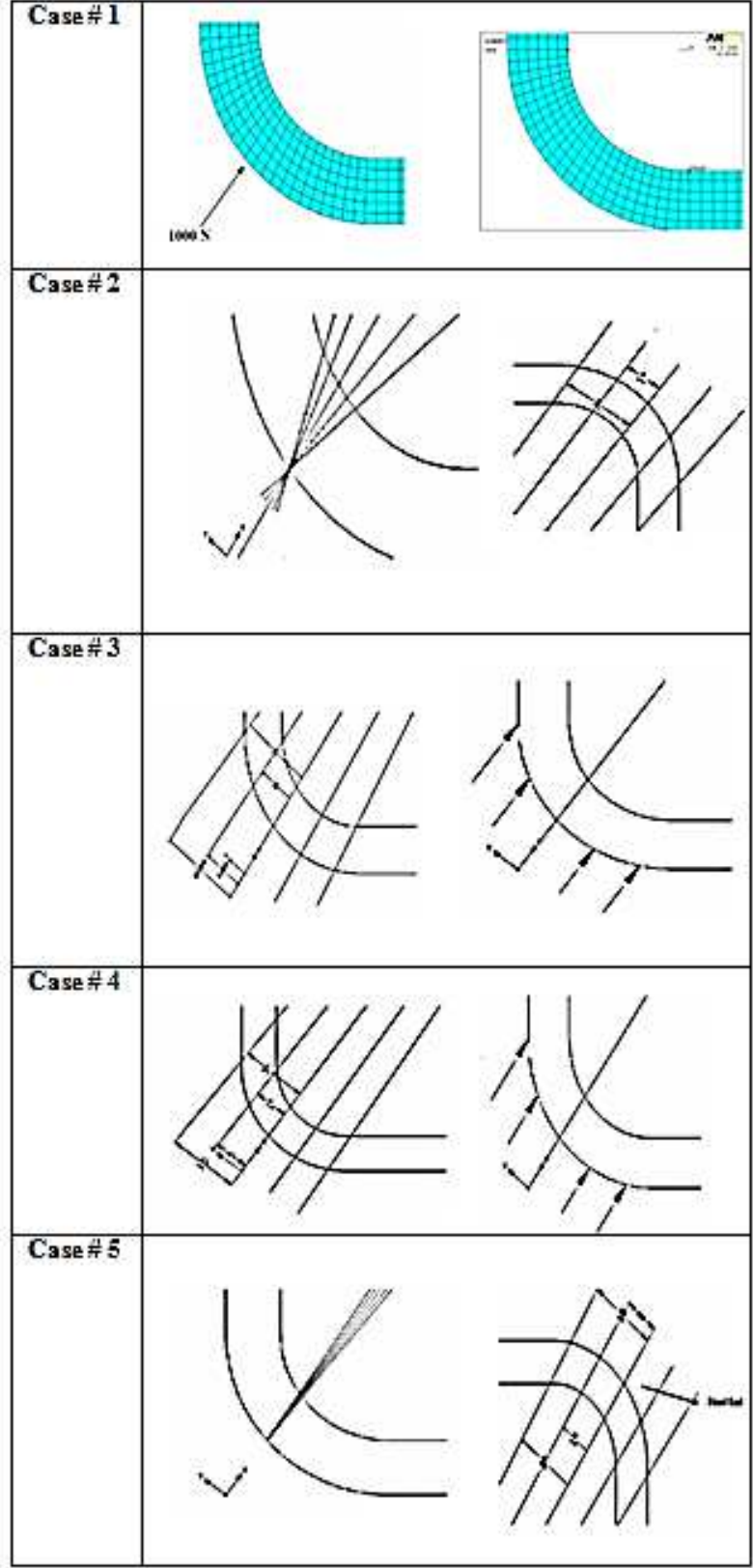

Figure 6. Investigated Cases Models.

Table 2. Micro-Strains in Different Locations.

\begin{tabular}{lll}
\hline Case \# & Position of Strain Gauge, Degrees & Strains (Microns) \\
\hline 1 & $0^{0}$ & 48.148 \\
2 & $17^{0}$ to x-axis & 48.150 \\
3 & $32^{0}$ to x-axis & 48.153 \\
\hline
\end{tabular}

\section{Results \& Discussions}

\subsection{Two-Dimensional Analysis}

It is clear from fig. 7 that micro-strains in distortion testing vary with change in position of fixed and pinned end of the tubes. The variation is not that significant but it is observed that the tube deforms more when the pinned end is positioned on the left side i.e. positive y-direction of the coordinate system.

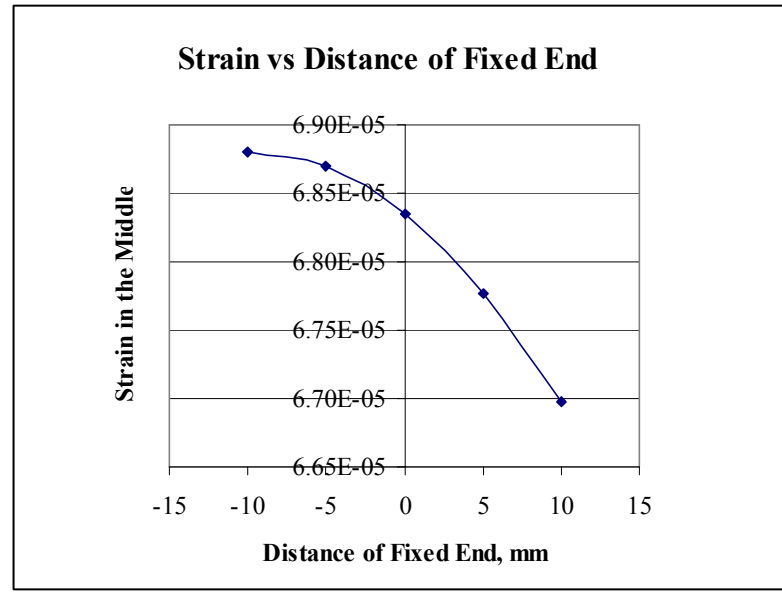

7. (a)
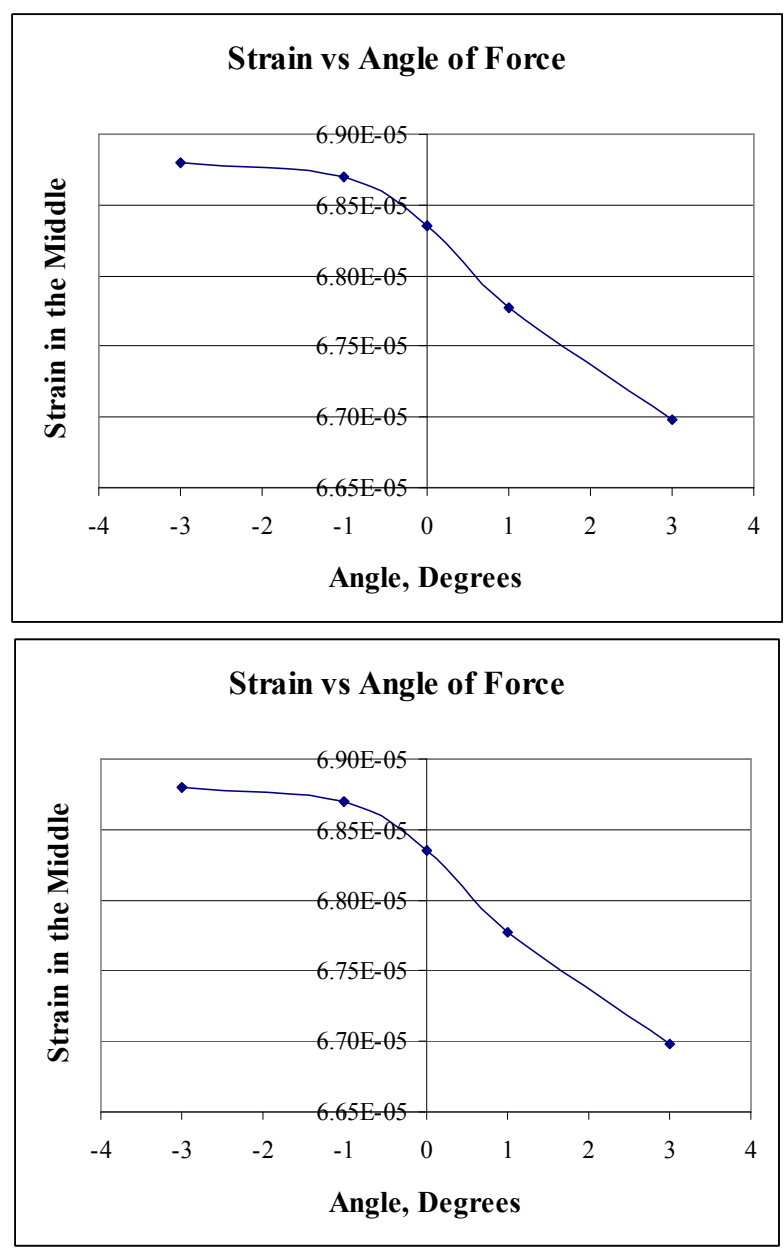

7. (b)

Figure 7. (a) and (b) Case 2 Plots.

It can be seen from figure (8) that when the position of both pinned end and the force end is varied with different angles and positions, the magnitude of micro-strains is also varied. However, the strains are maximum when the tube is placed at $5 \mathrm{~mm}$ in negative y-direction of the tube at lower side while $5 \mathrm{~mm}$ in positive $\mathrm{y}$-direction at upper side of the tube. 


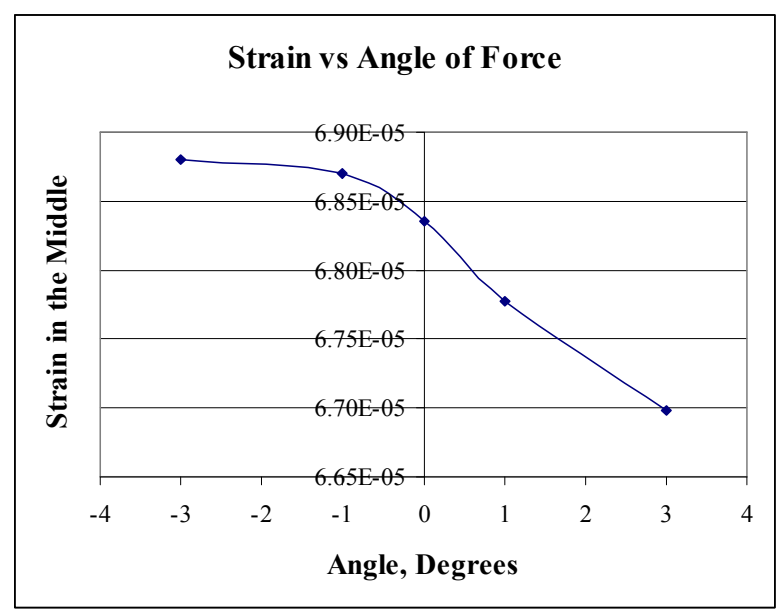

8. (a)

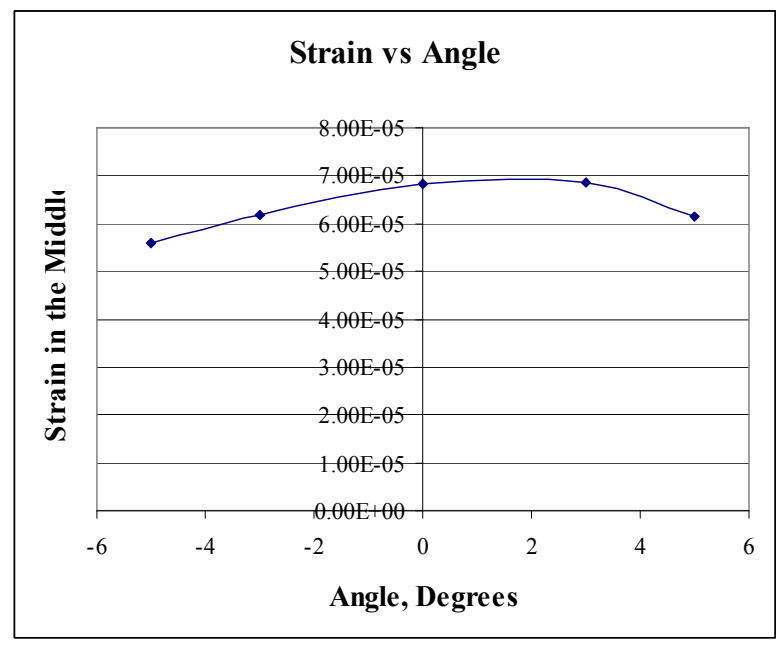

8. (b)

Figure 8. (a) and (b) Case 3 Plots.

When the position of pinned end is fixed and the position of force end is varied, the micro-strains again showed variations (fig. 9) in its magnitude with maximum value at 5 $\mathrm{mm}$ in negative $\mathrm{y}$-direction of the lower side of the tube.

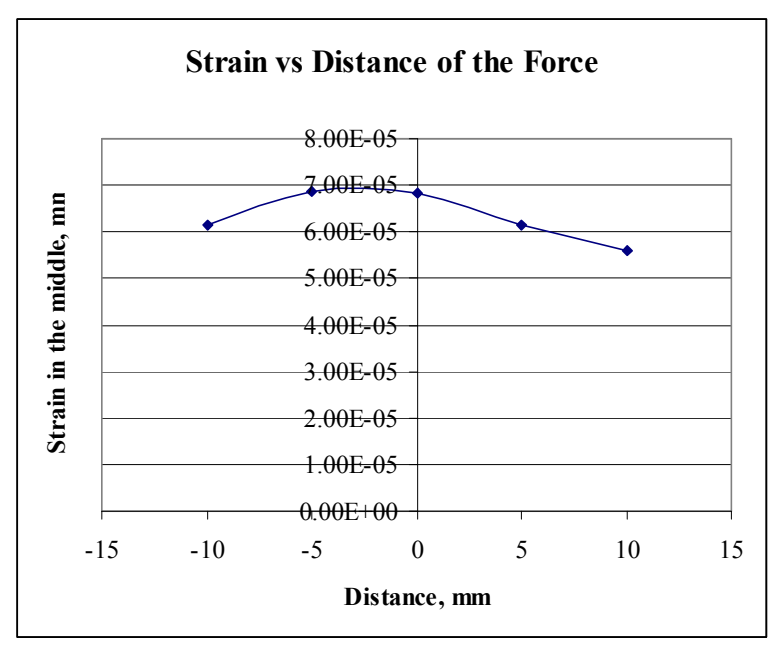

9. (a)

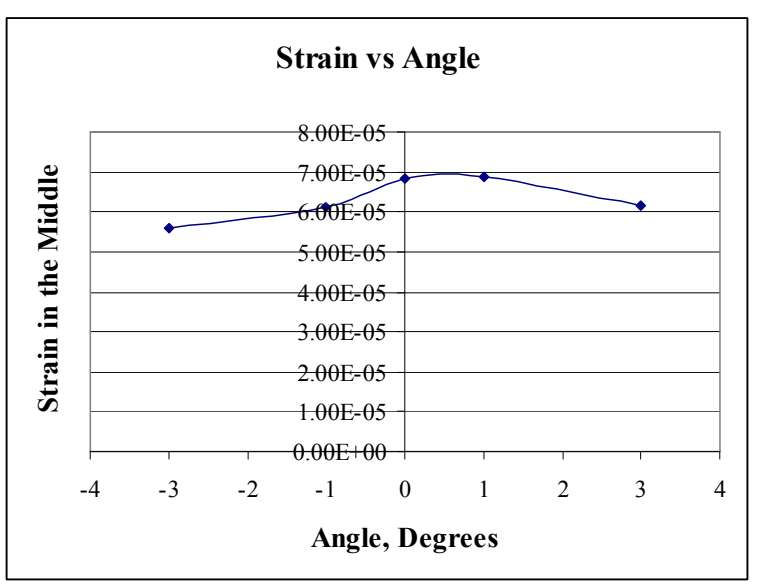

9. (b)

Figure 9. (a) and 9 (b) Variation of Strain w. r. t Angle.

In case 5 , the force end is fixed and upper (pinned) end is varied. The plot (fig. 10) clearly shows that when the pinned end is away from the middle corner of the tube the magnitude of the micro-strains are maximum. However, the variation observed not very significant.

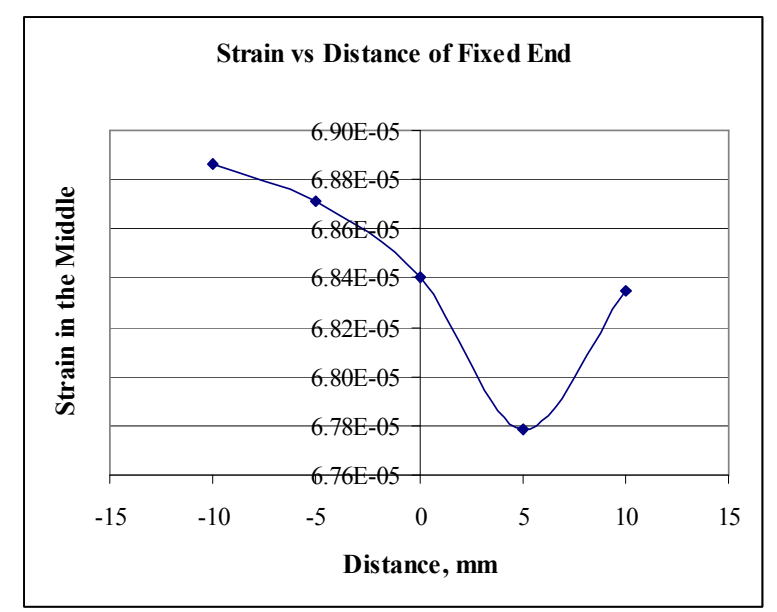

10. (a)

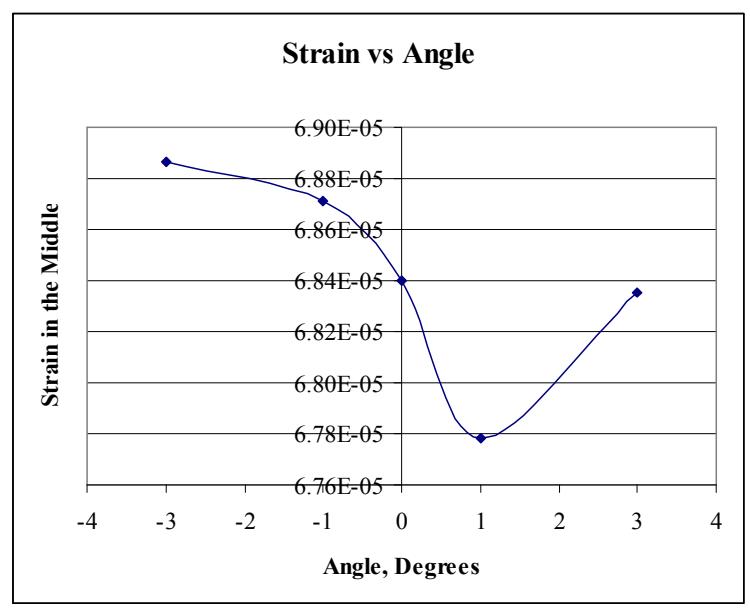

10. (b)

Figure 10. (a) and (b) Variation of Strain w. r. t Angle. 
Table 3. Investigated Cases.

\begin{tabular}{|c|c|c|c|c|c|c|c|}
\hline $\begin{array}{l}\text { Case } \\
\#\end{array}$ & Force $N$ & $\begin{array}{l}\text { Lower Side } \\
\text { Positionin } \\
\text { x-direction, } m m \\
\end{array}$ & $\begin{array}{l}\text { Lower Side } \\
\text { Positionin } \\
\text { y-direction, } m m\end{array}$ & $\begin{array}{l}\text { Upper Side } \\
\text { Position in } \\
\text { x-direction, } m m\end{array}$ & $\begin{array}{l}\text { Upper Side } \\
\text { Position in } \\
\text { y-direction, } m m\end{array}$ & $\begin{array}{l}\text { Lower Side Angle } \\
\text { from } \mathrm{x} \text {-axis, } \\
\text { Degress }\end{array}$ & $\begin{array}{l}\text { Upper Side Angle } \\
\text { from x-axis, } \\
\text { Degrees }\end{array}$ \\
\hline 1 & 1000 & 0 & 0 & 0 & 0 & 0 & 0 \\
\hline 2.a & 1000 & 0 & 0 & 0 & -5 & $1^{0}$ & $-1^{0}$ \\
\hline 2.b & 1000 & 0 & 0 & 0 & -10 & $3^{0}$ & $-3^{0}$ \\
\hline $2 . c$ & 1000 & 0 & 0 & 0 & 5 & $-1^{0}$ & $1^{0}$ \\
\hline $2 . \mathrm{d}$ & 1000 & 0 & 0 & 0 & 10 & $-3^{0}$ & $3^{0}$ \\
\hline $3 . \mathrm{a}$ & 1000 & 0 & 5 & 0 & -5 & $-3^{0}$ & $3^{0}$ \\
\hline $3 . \mathrm{b}$ & 1000 & 0 & 10 & 0 & -10 & $-5^{0}$ & $5^{0}$ \\
\hline 3.c & 1000 & 0 & -5 & 0 & 5 & $3^{0}$ & $-3^{0}$ \\
\hline $3 . d$ & 1000 & 0 & -10 & 0 & 10 & $5^{0}$ & $-5^{0}$ \\
\hline $4 . \mathrm{a}$ & 1000 & 0 & 5 & 0 & 0 & $-1^{0}$ & 0 \\
\hline $4 . b$ & 1000 & 0 & 10 & 0 & 0 & $-3^{0}$ & 0 \\
\hline $4 . c$ & 1000 & 0 & -5 & 0 & 0 & $1^{0}$ & 0 \\
\hline 4.d & 1000 & 0 & -10 & 0 & 0 & $3^{0}$ & 0 \\
\hline $5 . \mathrm{a}$ & 1000 & 0 & 0 & 0 & 5 & 0 & $1^{0}$ \\
\hline $5 . b$ & 1000 & 0 & 0 & 0 & 10 & 0 & $3^{0}$ \\
\hline $5 . c$ & 1000 & 0 & 0 & 0 & -5 & 0 & $-1^{0}$ \\
\hline $5 . \mathrm{d}$ & 1000 & 0 & 0 & 0 & -10 & 0 & $-3^{0}$ \\
\hline
\end{tabular}

\subsection{Three-Dimensional Analysis}

It is quite clear from plot (fig. 11) that the magnitude of micro-strains did not show any significant change in its value even for large value of angular misalignment. Hence the magnitudes of strain obtain from the distortion tests may be assumed to be valid due to the results achieved from FEA.

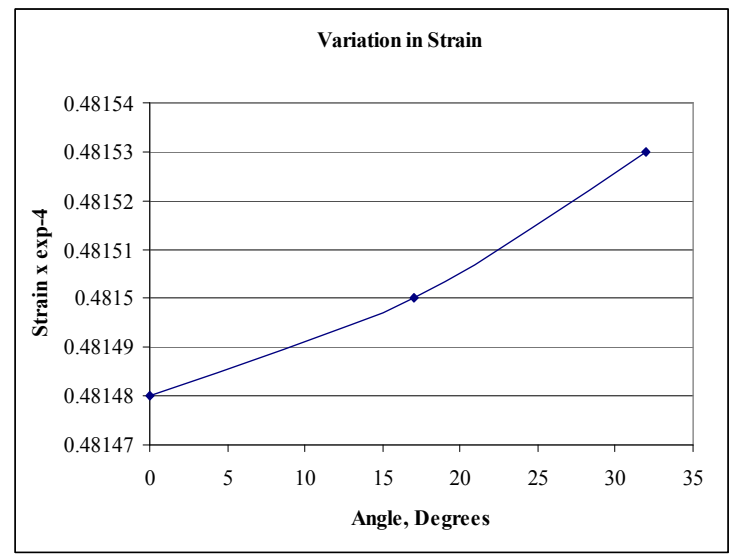

Figure 11. 3D Analysis Plot.

\section{Conclusion}

Two and three-dimensional Finite Element models have been developed for CFRHS tube using Ansys software and the micro-strains have been determined at the middle of the inner corner of the lower loaded side of the tube. From 2D analysis, the behavior of the micro elastic strain has been observed in the middle of the inner radius of the lower loaded side of the tube by changing either the location of force or the pinned end (upper end) or both and also by applying force at the middle node at some angle to the axis which is along the diagonal of the tube. From 3D analysis the behavior of the elastic micro strain at the middle of the inner side of the tube has been plotted by misaligning the location of the strain gauge. From both analysis the values of the strain in the middle of the inner side of the tube has been determined reported. However experimental investigations of these tubes are recommended to make comparison with computational results.

\section{Acknowledgements}

The author would like to appreciate the efforts of Mr. Sami Heinilla and Prof. Timo Bjork, faculty members, Lappeenranta University of Technology their valuable support in this work.

\section{References}

[1] Bäckström, M., Savolainen, M., Ilvonen R. and Laitinen R. In Proceedings of FATIGUE 2002, Stockholm, 2002, 277 - 302.

[2] Sami Heinilla, Timo Bjork, Gary Marquis, A study of curved crack paths in cold formed corners of high strength structural steels, Proceedings of Crack Paths (CP 2006), Parma Italy 2006.

[3] Assad Anis, Prediction of Residual Stresses in cold formed corners, Journal of Advanced Science and Engineering Research Vol 2, No 4 December (2012) 252-264, ISSN: 22318844 .

[4] Assad Anis, "Investigation of Stress Concentration Factors in cold formed rectangular hollow steel tubes", International Conference on Advanced Modeling and Simulation, 28-30 November 2011, Islamabad, Pakistan, ISBN:978-8698535-117.

[5] Assad Anis, "A Finite Element Analysis Approach to predict the stress concentration factors in Cold Formed Corners", International Journal of Mechanical \& Mechatronics Engineering, IJMME-IJENS Vol:12, pg 94-98, Issue: 04 ISSN:2227-2771. 
[6] Sami Heinilla, Gary B. Marquis, Timo Bjork, "Observations on fatigue crack paths in corners of cold formed high-strength steel tubes". Engineering Fracture Mechanics, Vol 75, issue 34, March 2008, Pages 833-844.

[7] Mohamed Dabaon, Ehab Ellobody, Khaled Ramzy, Experimental investigation of built-up-cold formed steel section battened column, Thin Walled Structures 92 (2015), $137-145$.

[8] Jason D. Gollarando, G. Avramovic Cingara, G. Palumbo, U. Erb, Microstrain and growth fault structures in electrodeposited nanocrystalline Ni and Ni-Fe alloys, Journal of Materials Science 48(19):6689-6699, October 2013.

[9] X. L. Xu. Y. Z. Chen, F. Liu, Study of microstrain in rapidly solidified structures of hypercooled $\mathrm{Co}_{80} \mathrm{Pd}_{20}$ alloys, Material Science \& Technology, Vol 29, 2013, Issue 1.
[10] Cheng Yu, Benjamin W. Schafer, Distortional Buckling Tests on Cold-Formed Steel Beams Journal of Structural Engineering, Volume 132 Issue 4 - April 2006.

[11] Sammy C. W. Lau and Gregory, Hancock, Distortional Buckling Tests of Cold-Formed Channel Sections, Ninth International Specialty Conference on Cold-Formed Steel Structures St. Louis, Missouri, U. S. A., November 8-9, 1988.

[12] R. Kandasamy, R. Thenmozhi, L. S. Jeyagopal, FlexuralTorsional Buckling Tests of Cold-Formed Lipped Channel Beams Under Restrained Boundary Conditions, International Journal of Engineering and Technology (IJET), ISSN: 09754024, Vol 6 No 2 Apr-May 2014.

[13] Thomas H.-K. Kang, Kenneth A. Biggs, and Chris Ramseyer, Buckling Modes of Cold-Formed Steel Columns, IACSIT International Journal of Engineering and Technology, Vol. 5, No. 4, August 2013. 